\title{
Design of an Interdigital Structure Planar Bandpass Filter for UWB Frequency
}

\author{
S. M. A. Motakabber, M. N. Haidari \\ Departement of Electrical and Computer Engineering, International Islamic University Malaysia, Malaysia
}

\begin{tabular}{l}
\hline \hline Article Info \\
\hline Article history: \\
Received Jan 2, 2018 \\
Revised Mar 19, 2018 \\
Accepted Mar 28, 2018 \\
\hline
\end{tabular}

Keyword:

Microstrip filter

Microwave substrate

Planar filter

Rreturnloss

Ultra-wideband technology

\begin{abstract}
A new topology of miniaturized interdigital structuremicrostrip planar bandpass filter for Ultra-Wideband (UWB) frequency has been discussed in this paper. The proposed design and its simulation have been carried out by using an electromagnetic simulation software named CST microwave studio. The Taconic TLX-8 microwave substrate has been used in this research. The experimental result and analysis have been performed by using the microwave vector network analyzer. The experimental result showed that the $-10 \mathrm{~dB}$ bandwidth of the filter is $7.5 \mathrm{GHz}$. The lower and upper corner frequencies of the filter have been achieved at $3.1 \mathrm{GHz}$ and $10.6 \mathrm{GHz}$ respectively. At the center frequency of $6.85 \mathrm{GHz}$, the $-1 \mathrm{~dB}$ insertion loss and the $-7 \mathrm{~dB}$ return losshave been observed. The simulated and experimental results are well agreed with a compact size filter of $19 \times 21 \times 0.5 \mathrm{~mm}^{3}$.
\end{abstract}

Copyright $\odot 2018$ Institute of Advanced Engineering and Science. All rights reserved.

\section{Corresponding Author:}

S. M. A. Motakabber,

Departement of Electrical and Computer Engineering,

International Islamic University Malaysia,

53100 Kuala Lumpur, Malaysia.

Email: amotakabber@iium.edu.my

\section{INTRODUCTION}

Potential applications of the UWB technology are, position measurement, short-range high-speed wireless communication, rescue radar systems, medical applications and so on [1]. Since 2002, the UWB technology has been regulated by the Federal Communications Commission (FCC) rules; hence any kind of design in this band must follow the FFC guidelines. Microstrip planar bandpass filter is an important component of the UWB system, which can be easily made under FCC regulations. A microstrip bandpass filter can offer extensive performance in the UWB communication. It is capable to select the required band and separating the different frequency ranges as the requirements. A microstrip line is a simple type of the transmission line which can be easily fabricated, miniaturized and connected with the microwave components [2].

In recent times, UWB bandpass filter is widely used in high-speed wireless data communication system because of its excellence [3]. In order to have a compact, cost-effective and easy integration with other microwave components the microstrip waveguide is one of the better options for designing a bandpass filter. Due to the huge potential, in recent times, many academic, research institutions and industries have focused on UWB technology. Various types of UWB microstrip filters are designed and developed. A bandpass filter with dual notched behaviour is reported in [4], a novel UWB bandpass filter is designed in [5], UWB filter with DGS is developed in [6], the U-shaped slot coupling structure is designed in [7] and UWB bandpass filter with CPW structure is developed in [8].

Though these filters have flat passband, low insertion loss and compact in size, however, most of these cover beyond the UWB frequency range. Consequently, they make interference with the licensed 
frequencies [6]-[9]. Hence still, efforts have been going on to design the filters with the capability of covering the entire UWB frequency range.

This article proposes a new structure of interdigital finger type microstrip bandpass filter that will cover the full range of UWB frequency only and do not interfere with any other band of frequency and devices. In addition, this compact planar structure bandpass filter provides a low insertion and return loss characteristics which are suitable for UWB application.

\section{FILTER DESIGNMETHOD}

The interdigital coupled line resonator with shunt stubs and square pads are used in the proposed Ultra-wideband bandpass filter. The interdigital resonators are used due to their high coupling degree [4]. The lengths of resonators according to Equation (3) are quarter wavelength $(\lambda / 4)$ at center frequency of $6.85 \mathrm{GHz}$. However, their lengths are varied to obtain the optimum result. The shunt stubs and square pads provide good lower passband. Varying the size of the two pads will vary the lower passband of the frequency response.

In order to design the bandpass filter a number of mathematical equations are used to calculate the filter parameters, the general formulas [8] are as follows.

Considering $W / h \leq 1$ (width to substrate ratio) and the substrate dielectric constant $\varepsilon_{r}$, the effective dielectric constant can be calculated by using the following formula.

$$
\varepsilon_{r e}=\frac{\varepsilon_{r}+1}{2}+\frac{\varepsilon_{r-1}}{2}\left\{\left(1+12 \frac{h}{W}\right)^{-0.5}+0.04\left(1-\frac{W}{h}\right)^{2}\right\}
$$

The characteristic impedance also can be calculated using the following equation.

$$
Z_{0}=\frac{\eta}{2 \pi \sqrt{\varepsilon_{r e}}} \ln \left(\frac{8 h}{W}+0.25 \frac{W}{h}\right)
$$

Where, the free space wave impedance is $\eta=120 \pi$ Ohms.

The effective dielectric constant is then used to calculate the lengths $L(\mathrm{~mm})$ of the resonators of the filter by using the Equation (3).

$$
L=\frac{300}{4 \times f \sqrt{\varepsilon_{r e}}}
$$

Where, $f$ is the center frequency of $\mathrm{GHz}$.

However, in order to get the optimum response, the lengths of the resonators should be slightly varied.

The coupling coefficient $M_{i, i+1}$ can be calculated by using Equation (4).

$$
M_{i, i+1}=\frac{F B W}{\sqrt{g_{i \times} g_{i+1}}}
$$

Where, the values of $g_{i}$ can be found in [8] and FBW is the fractional bandwidth that can be calculated using Equation (5).

$$
F B W=\frac{f_{U}-f_{L}}{f_{C}}
$$

The Taconic TLX-8 substrate has been used in this filter design which relative permittivity and thickness are 2.55 and $0.5 \mathrm{~mm}$ respectively. The total size of the bandpass filter is $19 \times 21 \times 0.5 \mathrm{~mm}^{3}$. The transmission line length L1 and width $\mathrm{W} 1$ are $4.75 \mathrm{~mm}$ and $1.34 \mathrm{~mm}$, respectively, which gives $50 \mathrm{Ohm}$ characteristic impedance. The L2 is $8 \mathrm{~mm}$ which is almost quarter wavelength based on Equation (3) and its width is, W2 $=0.28 \mathrm{~mm}$; the length of $\mathrm{L}$ is $8.25 \mathrm{~mm}$ and its width is $\mathrm{W} 2$. The spacing between the fingers is $\mathrm{S}=0.25 \mathrm{~mm}$; spacing between the fingers is very significant because the coupling between the resonators highly depends on the spacing; although due to the limitations of fabrication machine used to fabricate the filter; to make very small spacing is difficult. The length of the shunt stubs L3 is 7mm and its width W3 is $0.25 \mathrm{~mm}$; as well as the size of square pads is $4.7 \times 4.7 \mathrm{~mm}^{2}$. The shunt stubs and squared pads together act as an inductor and capacitor effect [3] respectively as a result, it helps to select a desired lower cutoff frequency easily. The ground plane and the microstrip lines of the filter are a copper plate and their thickness is $0.05 \mathrm{~mm}$. Figure 1 shows the schematic design of the filter. 


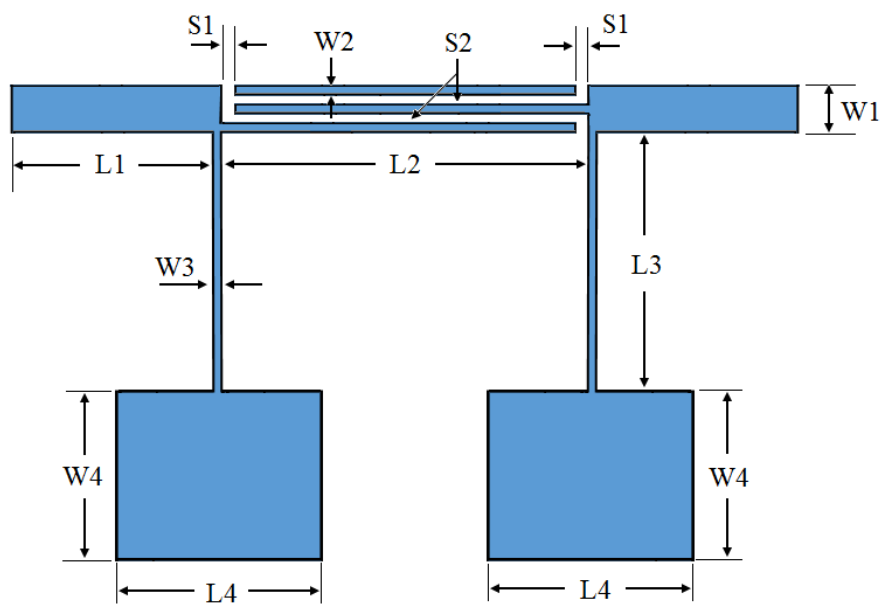

Figure 1. Layout of the UWB bandpass filter

The dimensions of the filter parameters are summarized in Table 1.

Table 1. Dimension of the Filter Parameters

\begin{tabular}{cccc}
\hline Filter parameter & Value $(\mathrm{mm})$ & Filter parameter & Value $(\mathrm{mm})$ \\
\hline $\mathrm{L}_{1}$ & 4.75 & $\mathrm{~W}_{1}$ & 1.34 \\
$\mathrm{~L}_{2}$ & 8.25 & $\mathrm{~W}_{2}$ & 0.28 \\
$\mathrm{~L}_{3}$ & 7 & $\mathrm{~W}_{3}$ & 0.25 \\
$\mathrm{~L}_{4}$ & 4.7 & $\mathrm{~W}_{4}$ & 4.7 \\
$\mathrm{~S} 1$ & 0.25 & $\mathrm{~S} 2$ & 0.25 \\
\hline
\end{tabular}

\section{RESULTS AND ANALYSIS}

This section illustrates the simulation result of the bandpass filter. The Ultra-wideband microstrip bandpass filter is designed and simulated with CST Microwave Studio; Figure 2shows the simulation result of the insertion loss $S_{21}$ and return loss $S_{11}$ of the filter respectively.

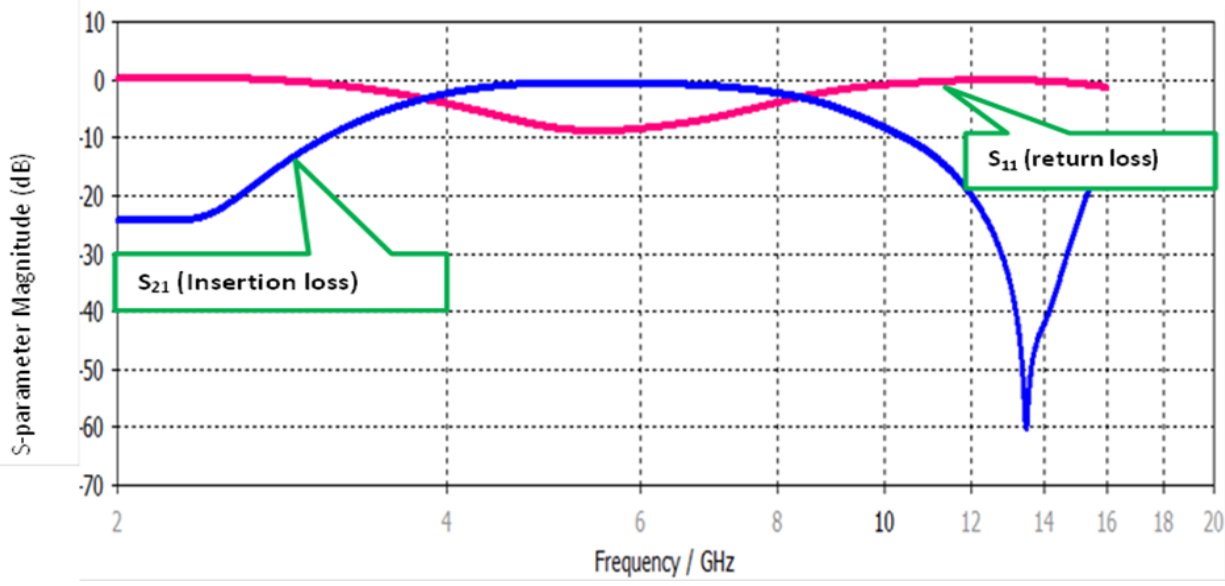

Figure 2. Simulation result of the insertion and return losses of the filter

The $10 \mathrm{~dB}$ bandwidth of the simulation result is $7.5 \mathrm{GHz}$, which covers the frequency ranges from $3.1 \mathrm{GHz}$ to $10.6 \mathrm{GHz}$. As the result, the proposed design does not interfere with any other devices. The center frequency of the proposed design is $6.85 \mathrm{GHz}$ and its insertion loss at the center frequency is less than $-1 \mathrm{~dB}$. The passband of the designed filter is uniformly flat. 
Figure 3 shows the snapshot of the realized filter. The proposed ultra-wideband bandpass filter is realized on TLX-8 Taconic substrate with dielectric constant of 2.55 and a thickness of $0.5 \mathrm{~mm}$. The size of the filter is compact.

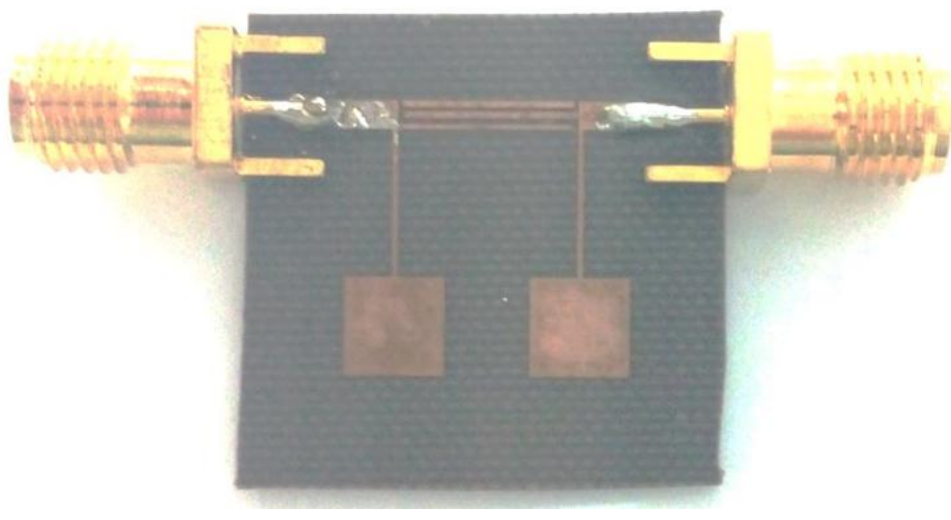

Figure 3. Photograph of the prototype filter

Figure 4 shows the experimental result of the prototype filter. The filter response is verified by a Vector Network Analyzer (model: N5230A PNA-L). It can be seen from Figure 4, the passband of the filter is not flat and considering the $10 \mathrm{~dB}$ bandwidth, it covers from $3.2 \mathrm{GHz}$ to $9 \mathrm{GHz}$.

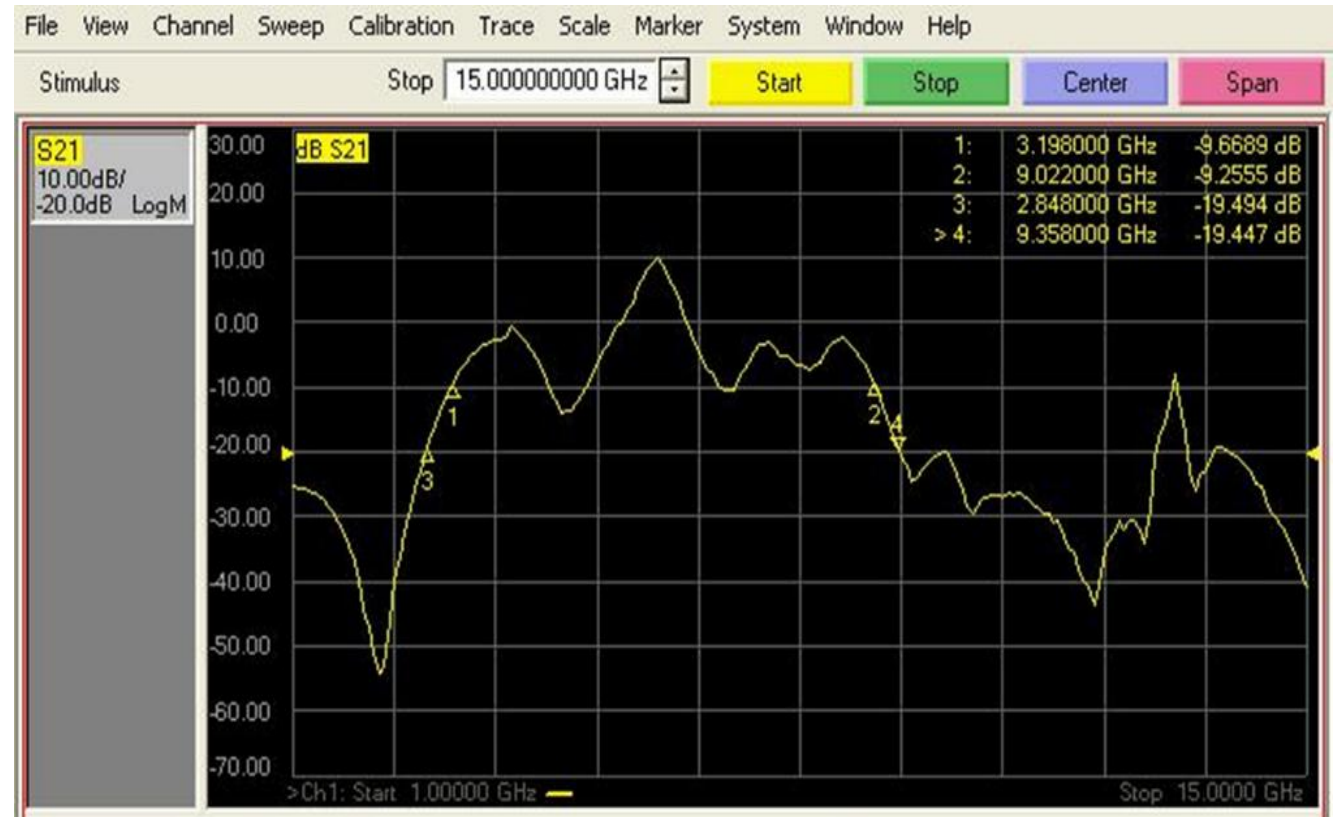

Figure 4. Experimental result of the developed filter

The experimental and simulation combined results are shown in Figure 5. Comparing the CST simulation result with the prototype filter, the lower cutoff frequency has increased about $3 \%$ and the upper cutoff frequency has decreased about $15 \%$ in the realized filter. The reason of the differentbandwidth, as well as the cutoff frequencies, is due to the fabrication impairments of the filter. There might be some corrosions in the surface of the strips as well as in the ground plane of the filter which might take place during the etching process that affected the results. 


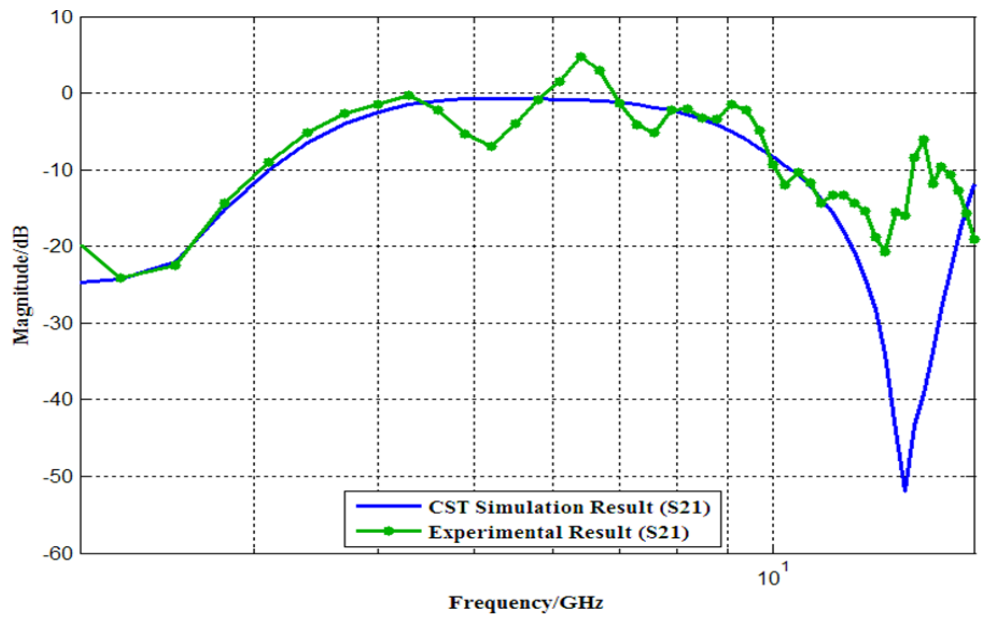

Figure 5. Experimental and CST simulation combined results

\section{CONCLUSION}

This paper presents the design and implementation of a compact quarter wavelength UWB bandpass filter. The filter is designed using the interdigital coupled lines, two shunt stubs and two squared pads. The interdigital line filter used three fingers; two of which are connected with the input and output transmission lines and the third one is free that is, it is not connected with anything. The $-10 \mathrm{~dB}$ passband of the filter is not completely flat; however, it can be improved by adjusting the degree of coupling. This filter has a compact size and can be used for high-speed communication devices. The passband response of the filter is within the UWB frequency range and does not make interference with another band of frequency. In order to improve the passband response and sharp transition between the passband to the stopband, more finger can be added and by adjusting the spacing and widths of the fingers

\section{ACKNOWLEDGEMENTS}

This research has been supported by the Malaysian Ministry of Science and Technology through the Science Fund under the project ID: SF14-010-0060.

\section{REFERENCES}

[1] Z.C. Hao and J.S. Hong, "Ultra-Wideband Filter Technologies", IEEE Microwave Magazine, vol. 11, no. 4, June 2010

[2] J.S. Hong, and M.J. Lancaster, "Transmission Lines and Components: Microstrip Filters for RF/Microwave Applications", Wiley Series in Microwave and Optical Engineering, pp. 79-80, 2001.

[3] S. Kumari and M. Kumar, "Design of Planar Bandpass Filter for Ultra-Wideband Applications", 4th Int. Conf. Communications Systems and Network Technologies, pp. 38-40, 2014.

[4] S. Kumari and M. Kumar, "Ultra-Wideband Planar Bandpass Filter with Dual Notch Behavior", IEEE Int. Conf. Advances in Engineering \& Technology Research, August, 2014, Unnao, India.

[5] W. Tang et al., "A Novel UWB Bandpass Filter Using Highpass and Lowpass Filters", IEEE 4th International High-Speed Intelligent Communication Forum, May 2012.

[6] S. Lavanya, M.U. Maheshwari et al, "Planar Ultra-Wideband Bandpass Filter Using Defected Ground Structure", IEEE 2nd Int. Conf. Innovations in Information Embedded and Communication Systems, 2015.

[7] G. M. Yang et al., "Planar Microstrip UWB Bandpass Filter Using U-shaped Slot Coupling Structure", Electronics Letters, vol. 42, no. 25, Dec 2006.

[8] H. Wang et al., "Ultra-Wideband Bandpass Filter with Hybrid Microstrip/CPW Structure", IEEE Microwave and Wireless Components Letters, vol. 15, no. 12, pp. 844-846, Dec 2005.

[9] Y. Gaurav and R.K. Chauhan,“ A Compact UWB BPF with a Notch Band using Rectangular Resonator Sandwiched between Interdigital Structure", International Journal of Electrical and Computer Engineering (IJECE), vol. 7, no. 5, pp. 2420-2425, 2017. 